\title{
Evaluating National Innovation System of Malaysia Based on University-industry Research Collaboration: A System Thinking Approach
}

\author{
Abeda Muhammad Iqbal ${ }^{1}$, Adnan Shahid Khan ${ }^{2}$, Farrukh Bashir ${ }^{3}$ \& Aslan Amat Senin ${ }^{1}$ \\ ${ }^{1}$ Faculty of Management, Universiti Teknologi Malaysia, Johor, Malaysia \\ ${ }^{2}$ Faculty of Computer Science and Information Teechnology, Universiti Malaysia Sarawak, Malaysia \\ ${ }^{3}$ Faculty of Business and Law, Federation University Australia, Australia \\ Correspondence: Abeda Muhammad Iqbal, Faculty of Management, Universiti Teknologi Malaysia, Johor, \\ Malaysia. E-mail: abidaiqbal49@yahoo.com
}

Received: September 28, 2014 Accepted: February 24, $2015 \quad$ Online Published: May 16, 2015

doi:10.5539/ass.v11n13p45 URL: http://dx.doi.org/10.5539/ass.v11n13p45

\begin{abstract}
National innovation system (NIS) is an essential, effective and dynamic factor for the development of the nation. Despite the enormous research activities on NIS, there have been certain issues still remaining in this domain specially, in developing countries. Several articles have been published to deal with the factors affecting NIS of Malaysia but the role of research collaboration between university and industry (UIRC) on NIS is totally unattended in mainstream literature. Thus, the objective of this study is to determine the influence of UIRC on the NIS of Malaysia. Additionally, this study aims to indicate the current innovation performance and to identify the existing constraints of NIS. For the purpose of system modeling, system thinking approach is used to conceptualize and analyze the effect of UIRC on NIS. The result of this research shows that constraints of UIRC in Malaysia negatively influence on the success of NIS.
\end{abstract}

Keywords: national innovation system, university-industry research collaboration, evaluation, system thinking, innovation

\section{Introduction}

The concept of national innovation systems (NIS) has been gaining intellectual and practical coherence over a number of decades, enjoying initial strong adoption by OECD and developed countries, and more recently becoming the focus of increased attention as a means to address some of the more profound issues for developing nations (Castellacci \& Natera, 2013). The growing number of studies of innovation systems shows that the creation of innovation-enhancing framework by evaluating the existing conditions of NIS has become a central target of policy makers around the globe (Marxt \& Brunner, 2012). Innovations are considered the engine of productivity and competitiveness (Autant-Bernard, Fadairo, \& Massard, 2013). Innovation is a complex process that involves not only the innovative firm but also a system of interactions and interdependencies between firm and other organisations and institutions (Metcalfe \& Ramlogan, 2008; Saeidi, et al., 2013). In this regard, for the development and improvement of national innovation system capabilities, collaboration between universities and industries is widely recognized as one of the key factors (Jin, 2011; Teirlinck \& Spithoven, 2013). Recently, many studies provide pieces of evidence for the strategic importance of the University- Industry research collaboration that produce a very huge impact on national economies (Fiedler \& Welpe, 2010; Robin \& Schubert, 2013). In the recent era of increasing competition, many nations compete to improve innovative capability with an aim for the growth and economic performance of the economy (Boons et al., 2013; Popescu \& Crenicean, 2012). And the university-industry research collaboration is a key evaluating factor that provides possible pathways to accelerate the process of technological catch-up as well as sustain productivity growth and competitiveness (Bayarçelik \& Taşel, 2012). Malaysia's innovation performance is in line with that of other middle-income countries in the Southeast Asian region, but shows a significant gap with high income countries. The World Bank's Knowledge Economy Index which captures the ability to generate and diffuse knowledge, ranked Malaysia 48th out of 145 countries (KEI, 2012), that demand serious efforts to enhance the technological innovation and development in Malaysia. Effective technology development in a country depends on the 
networking and linkages among public and private institutions that shape technological capabilities (Beaudry \& Allaoui, 2012; Boardman, 2009; Chen \& Guan, 2010; Fiaz, 2013). In this regard, collaboration between university and industry is one of the most prominent institutional interfaces to make their role more benefit to national economic development and to support the growth of high technology activities in the country. A substantial amount of research has been devoted to the investigation of university-industry collaboration in Malaysia but less attention has so far been given to the analysis of the dynamics of university-industry collaboration on the context of NSI. Thus, this study attempts to fill this gap by examine the role of university-industry research collaboration and its effect on NSI in Malaysia.

Secondly, it is also analysed that a very few studies were conducted to evaluate the NIS by analysing the role of linkages and networking, specifically, linkages between university and industry in Malaysia. For instance, (Ramli, 2013) highlighted that Malaysian research universities are still in infancy stage. Author argued that research and development $(\mathrm{R} \& \mathrm{D})$ activities should be developed properly in order to ensure impressive outcome and not just some non-useful invention. Moreover, the author argues that Malaysian industries also need to play active role in developing their R\&D at the same time. They should also seek local expertise within local universities in developing their technologies instead of looking at the foreign expertise oversees. By realizing a great interest and importance of university and industry, to the author knowledge, none of the researcher evaluated the influence of university-industry research collaboration on NIS in Malaysia extensively. Since, the university-industry research collaboration has a strong and direct impact on all the determinants of NIS that increase the technological and economic growth of any nation, policy makers need to have a comprehensive understanding of the exact existing condition of the country' R\&D. To fill this gap, this study aims to evaluate the NIS of Malaysia by investigating the effect of university-industry research collaboration. The paper is structured as follows:

The next section presents the literature review and hypothesis development. Section 3 elaborates the modeling approach using system thinking. Section 4 provides the evaluation model using system dynamics. Followed by the section 5 we conclude and discuss this paper.

\section{Literature Review}

Several studies were conducted to enhance the innovative capability of NIS from the perspective of different determinants in Malaysia. For instance, (Govindaraju \& Wong, 2011), found foreign firm's activities highly effects the patenting trends in Malaysia and considered this issue as an impending factor of NIS. Wong \& Goh, (2010), highlighted the weaknesses of Malaysia with the comparison of Thailand and Singapore. Wong, Thirucelvam, \& Ratnavelu, (2010), also found out that the growth behaviour of patent and publication is a major impending factor of NIS. Author suggest that improvements in the innovation system is essential to advance and stimulate further development of science and technology for Malaysia but the number of patents and publications that is being produced by Malaysia is slow. The researcher indicates some policy features that are associated with a strong increase in demand for patents to strengthen the NIS. These policy features are include in policies aiming at attracting FDI, low relative cost (or fees), and a relatively low quality of the examination processes. (Ahmed, 2012), investigated the effects of FDI inflows on human capital, labour force, absorptive capacity and physical capital and shows that FDI plays a significant role in achieving economic growth in Malaysia. In another research of (Govindaraju, 2005), provide evidence that Malaysia still lacks in placing the proper mechanism especially with regards to education, $R \& D$ and other fundamental mechanisms to accelerate the process of innovation in the country. (Heng, Rasli, \& Senin, 2012), suggest that university commercialisation play a major role in the national economic growth. For this purpose he provided a knowledge determinant to enhance innovator's perception towards commercialisation. Wonglimpiyarat (2011), found financing as an important determinant to enhance NIS and explore government programmes in financing innovation using comparative innovation system cases of Malaysia and Thailand.

For the purpose of evaluation, this study explores all the constraints that exist in NIS of Malaysia. For instance, the establishment of formal intellectual property systems in Malaysia is rather slow and embedded in more complex judicial systems. Although the IPR systems of Malaysia have improved, but low prosecution rates of infringements opposed to high rates of infringements suggest that their enforcement of patent rights were still considered weak and inefficient $(\mathrm{Vu}, 2012)$. Similarly, it is well recognized that a trained, skilled and well-educated workforce is critical in enhancing work and economic performance and sustaining competitiveness. Although, Malaysia demonstrated a significant achievement in research and development, the extent of manpower for R\&D is still well below the minimum needed to perform R\&D activities (Asgari, 2007; Govindaraju \& Wong, 2011). The R\&D expenditure by type of research in Malaysia is dissimilar to that in the NIEs. The biggest portion of the R\&D expenditure in Malaysia is used for applied research. Meanwhile, basic 
research constitutes the smallest portion of the total R\&D expenditure. This suggests that they all mainly focus on a particular application or use rather than to increase the knowledge. It is widely acknowledged that the growth of knowledge based economies is fuelled by research and development (R\&D) and technological innovation. For the measurement of knowledge spill overs patents and publications have generally been accepted as indicators of the innovation and R\&D process (Griliches, 1992). The inability of existing firms to shift towards higher value added activities, the scarce supply of engineers and R\&D scientists and technicians, low private $R \& D$ investment and less number of qualified Malaysians had compounded the problem of slow growth in the number of publications and patents, produced in Malaysia. (Azizan, 2013; Chandran VGR, 2009). The estimated prolongation ability of the newly industrialized economies (NIEs) including South Korea, Taiwan and Singapore suggests significant transformation of their innovation system that led to a higher degree of functionality and infrastructure, while developing economies such as Malaysia due to low technological infrastructure shows no significant change over the years (Asgari, 2007). Simultaneously, it has been observed that FDI has played a very important role in shaping Malaysia's economy over its history. However, its spill overs effect has insignificant impact on Malaysian economy. According to the Ahmed (2012), the contribution of, FDI in the Malaysian economy is as high as the contribution of physical capital and labour that negatively affect the human capital, and absorptive capacity to achieve productivity driven economy. With the major constraints of NIS it has also been observed that the development of research university system in Malaysia is still at infancy stage compared to RU in the United States and United Kingdom (Ramli et al., 2013). R\&D resources provided by MOSTI's to GRIs and universities always have low industrial-oriented values research that decrease the interest of private sector in country's R\&D and the number of commercialization (Asgari, 2007). From all above mentioned literature and from the existing constraints of NIS, this study that the sequential and fundamental cause of weak NIS of Malaysia is the weak research collaboration between university and industry. Thus this study hypothesises that:

\section{H1: Constraints of University-industry research collaboration have negative effect on the success of NIS.}

HIa: lack of education and training between UIRC has negative effect on technological infrastructure and quality of research.

H1b: lack of education and training between UIRC has negative effect on Human capital.

H1c: lack of education and training between UIRC has negative effect on Patents and publication.

H1d: Time constraints and lack of technological competency between UIRC has negative effect on Absorptive capacity and on patents and commercialization.

H1e: Conflict of intellectual property right between UIRC has negative effect on national IPR system

H1f: lack of consultancy between UIRC has negative effect on patents and commercialization.

HIg: Culture difference between UIRC has negative effect on Private sector involvement in R\&D.

HIh: Fund and financial matter between UIRC has negative effect on investment in R\&D and FDI.

Table 1. Constraints of UIRC and NIS

\begin{tabular}{ll}
\hline Constraints of UIRC & Constraints of NIS \\
\hline Lack of education and training & Weak intellectual property right system \\
$\begin{array}{l}\text { Conflict of intellectual property } \\
\text { rights }\end{array}$ & Poor human capital \\
Time constraints & Low investment in R\&D \\
Lack of technological competency & Less number of publications and patents \\
Culture difference & Low technological infrastructure \\
Fund and financial matter & Low absorptive capacity \\
Lack of consultancy & High dependencies on foreign direct investment \\
& Number of patents less commercialization \\
& Low quality of research in government research institutes and \\
& universities \\
& Lack of private sector involvement in R\&D \\
\hline
\end{tabular}


Iqbal et al., (2011), provided constraints of UIRC in Malaysia, who explicitly argued that lack of education and training, conflict of intellectual property rights, time constraints, lack of technological competency, culture difference, fund and financial matter and lack of consultancy are the critical constraints of UIRC. So the effect of each constraints of UIRC on NIS will be presented in the following section by using system thinking approach. Table 1 shows all the constraints of NIS and UIRC that are inhibiting the efficiency of NIS of Malaysia.

\section{Modelling Approach}

System Thinking Approach developed in WWII (Checkland, 1999), dealt with complex problems of policy making or military planning (Patching, 1990). Systems thinking approach composed of three stages (Flett, 2001) 1) Discovering the interrelationships between the components of the system; 2) Drawing an influence diagram' in order to illustrate and analyze these relationships and verify their behavior; 3) Using system dynamics in order to model and simulate the system in a different situation.

A soft systems modeling approach "the system dynamics" has been selected by the author in order to develop evaluation model (Galanakis, 2006; Coyle, 1996). System dynamics deals with the time-dependent behavior of managed systems with the aim of describing the system and understanding, through qualitative and quantitative models, how information feedback governs its behavior, and designing robust information feedback structures and control policies through simulation and optimization. The selection was made on the basis of the ability of the methodology to handle both quantitative and qualitative variables, the level of development of existing supportive computer-based modeling packages and the proximity of the roots of the system dynamics to an engineering way of thinking, that is, control systems engineering. Although the methodology has its roots in engineering, which can be traced to the work of Tustin (1953) and Forrester (1961), it is commonly used in business administration and public policy analysis (Pidd, 1998). Pidd (1998) has showed how such an approach could be used to understand, control and develop these kinds of systems. Systems dynamics concentrates on the study of the connections between the different elements as well as the behavior of the whole (Roberts et al., 1983). The feedback structures and the system's short- and long-term response to them determine how the policies of change are designed and in which direction, to satisfy targets that are set (Pidd, 1996).

Thus, this methodology can be used to analyze innovation theory and the factors that affect innovation system using a commonly understood methodology. This methodology is based on the development of a series of influence diagrams (often called causal loop diagrams), which were first suggested by Maruyama (1963). These diagrams represent the forces that occur in a system and between its parts. The essential idea behind the influence diagrams is an information-action-consequences paradigm. In this paradigm the consequences are always physical in the sense that something flows in the system. The recognition of what flows in the system is the key element to a good model (Coyle, 1996). The action that is based on the information that has been collected creates consequences that may appear after some time (delay). These consequences generate further information and actions which may, in turn, continue the process. The dynamic behavior of the information/action/consequences paradigm is the basis of any analysis. Four fundamental flows have been identified which, in combination, create the influence diagrams of any system (Senge, 1990): Reinforcing Loop, Balancing Loop, Fixes that Fail and Shifting Effect Loop. However, this study used two flows to develop the model of this research. Reinforcing loop and balancing loop.

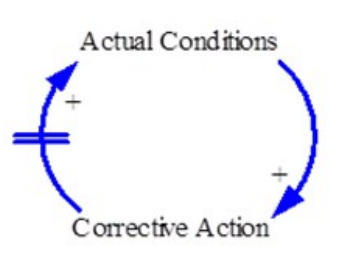

Figure 1. Reinforcing loop

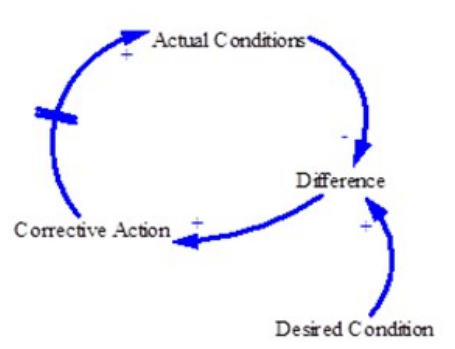

Figure 2. Balancing loop

Reinforcing loop (Figure 1) is an open loop control system, where its output will continue to increase or decrease without a limit as long as the input (action) increases or decreases. A person or an organization that is not aware of the delay may take more corrective action than needed, or give up because they cannot recognize that any progress has been made. While the Balancing loop brings (Figure 2) one additional factor, which creates a target 
or a limitation which the final condition of the system can take, creating a close loop control system. This target is compared to the actual state of the system, in order to provide information about the next action that its outcome will bring to the new status of the system's output. The delays in this system are critical factors for the ability of the system to be stabilized and should be considered in the design of each action. Based on theory of system thinking, following section will present the effect of constraints of UIRC on NIS.

\section{Evaluation Model Using System Dynamics}

a) Lack of education and training between UIRC, low technological infrastructure and low quality of research.

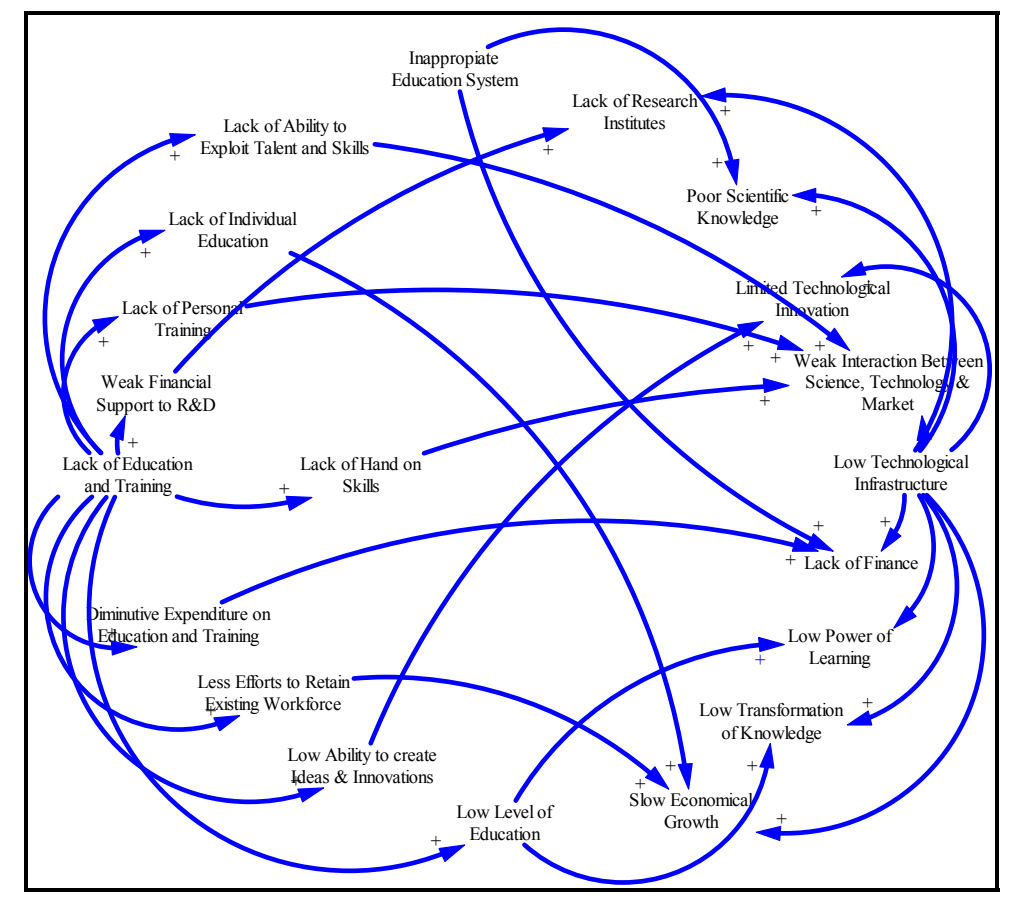

Figure 3. Education and training and technological infrastructure influence diagram

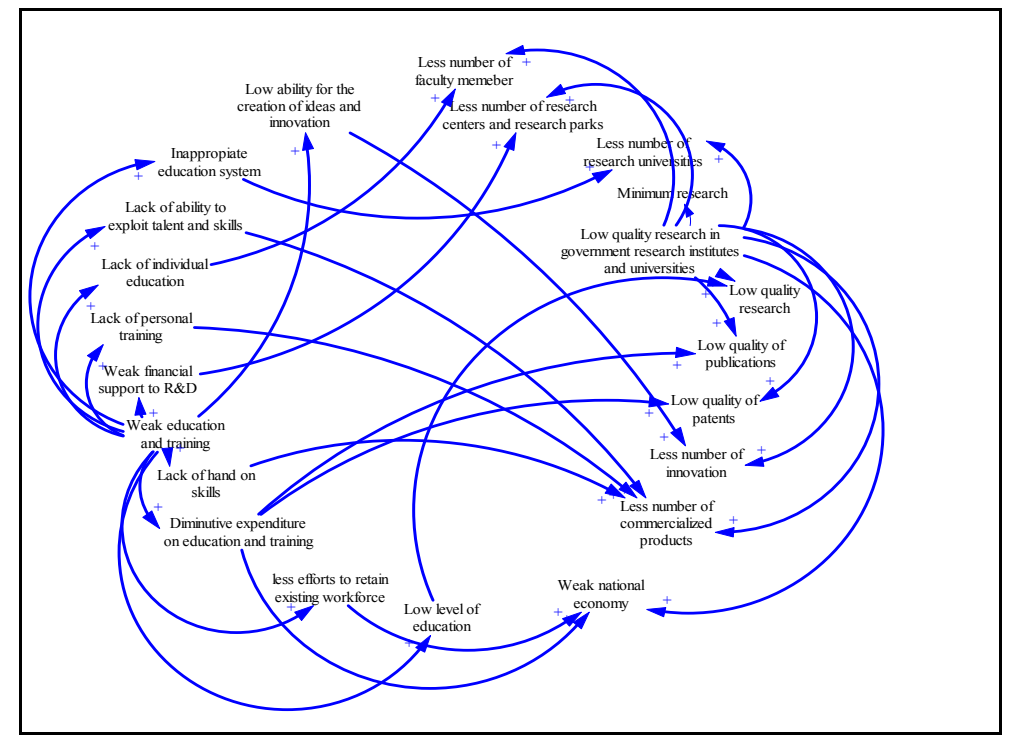

Figure 4. Education and training and quality of research influence diagram

National innovative capacity depends critically on the quality of the technological infrastructure (such as the supply of scientists and engineers and the number and quality of research institutions), the degree of government support for basic research, the collaboration between research universities and industries. lack of dynamic national 
institutional set-up, limited expenditure on education and training resulting in low quality of research and weak interaction between science, technology and market oriented activities, thereby causing poor infrastructure in a country (Wong \& Goh, 2012). A country's technological infrastructure encompasses the education system, quality of research, the network of research organizations, and the legal framework that protects intellectual property rights and provides incentives to create and exchange technologies. To develop the quality of research and technological infrastructure, a well-structured policy that stimulates the collaboration between different public, private organizations are the main instruments to enhance education, training, skills and knowledge Iqbal et al., (2013). The educational level and quality of research are clearly important aspects of a country's capacity for innovation. It is probably just as difficult for an economy located far from the technological frontier to adapt and use existing technologies, with an uneducated workforce, as it is for an economy at the technological frontier to create new technologies with a highly educated workforce (Pavitt \& Patel 1999). Figure 3 and 4 shows the effect of lack of education and training on technological infrastructure and quality of research.

\section{b) Lack of education and training between UIRC and human capital.}

Smith (2010) argued that economic growth depends not only on physical capital such as machines, factories and tools but also investment in human factor. Human capital is the most important element in determining a country's ability to innovate. Becker (1993), views human capital as organizational assets whose economic value is derived from knowledge skills, competence and experience. Schultz (1993) defines human capital as human abilities in which learning and skills are embedded. For the rapid progress of firms restructuring and the diversification of manufacturing, technological knowledge and the abilities of human capital skills is necessary. Establishment of new scientific institutions and greater opportunities of education and training upgrade the quality and skills of the human capital (Lanciano-Morandat \&Nohara, 2002). Simultaneously, Lifelong learning is important in producing multi skilled human capital that is able to cope with continuous technological change. As knowledge is not static, it is important for publics to be given opportunities to continue learning throughout their lifetime. To encourage lifelong learning, learning institutions such as universities should offer programs in order to enhance skill mobility. Lack of education and training between university-industry research collaboration leads to a decrease in the human capital. Figure 5 shows the effect of lack of education and training on human capital.

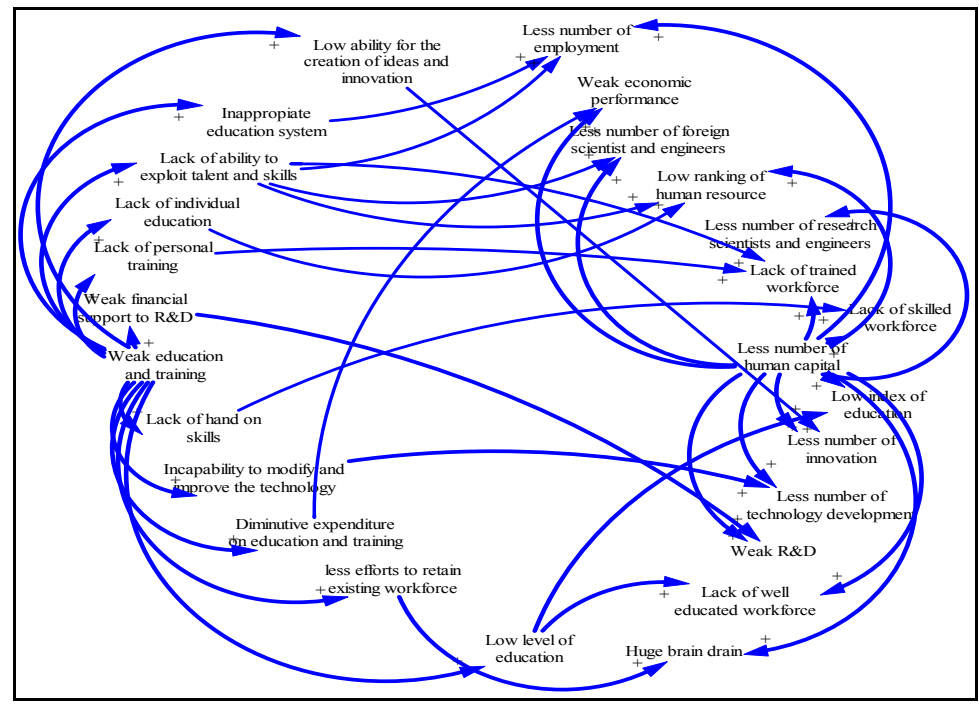

Figure 5. Education and training and human capital influence diagram

\section{c) Lack of education and training between UIRC and less number of patents and publications.}

Bibliometric indicators used to measure research performance are mainly based on two central elements i.e., number of publications and patents. The statistics based on the number of publications primarily reflect the quantitative output of research activity. Ahmed et al. (2012), provide positive relationship between education and training and research productivity. The result of the research reveals that proper channels of education and training between public and private organizations increases the number of patents and publications. Education brings significant benefits to society, not only through higher employment opportunities and income but also via enhanced research skills, improved social status and access to networks (Ahmed et al., 2012; Bashir et al., 2013). 
There are a number of reasons why some countries publish more than others but it is no real surprise that the USA produces the most scientific papers with the help of their highly educated and trained personals in their public and private organizations. The facts indicate that during the period of 1999-2009, there were 2.9 million scientific papers published in the USA according to Essential Science Indicators at Thomson Reuters (Young, 2011). Eid (2012) examine the impact of higher education R\&D and its impact on productivity growth in 17 high-income OECD countries using country level data over the period 1981-2006. The results suggest that R\&D performed by highly educated and trained personals is positively affecting productivity growth in all specifications. The long-run propensity of productivity growth to R\&D performed by the higher education sector is also found to be positive and significant.

Universities, and higher education systems worldwide, are being transformed by new or changing practices, programs, policies, and agendas. From notions of 'global competency' and the 'global engineer,' through to ever more common perceptions that international collaborative research is a desirable objective, through to the phenomena of bibliometrics, rankings and benchmarking that work at a global scale, contexts are changing (Old \& Robertson, 2013; Iqbal et al., 2013).Many studies focused on science and technological diffusion taking place in selected emerging countries in Asia, including, Park et al. (2005), studied the publication trends in Asia. Hu and Tseng (2007) examined knowledge diffusion in building the competence of innovation in China and Taiwan by using data on patents from USPTO and publication statistics from ISI. The studies demonstrated that because of substandard education system, these countries do not show significant changes in publications and patents. Figure 6 shows the effect of lack of education and training on patents and publications.

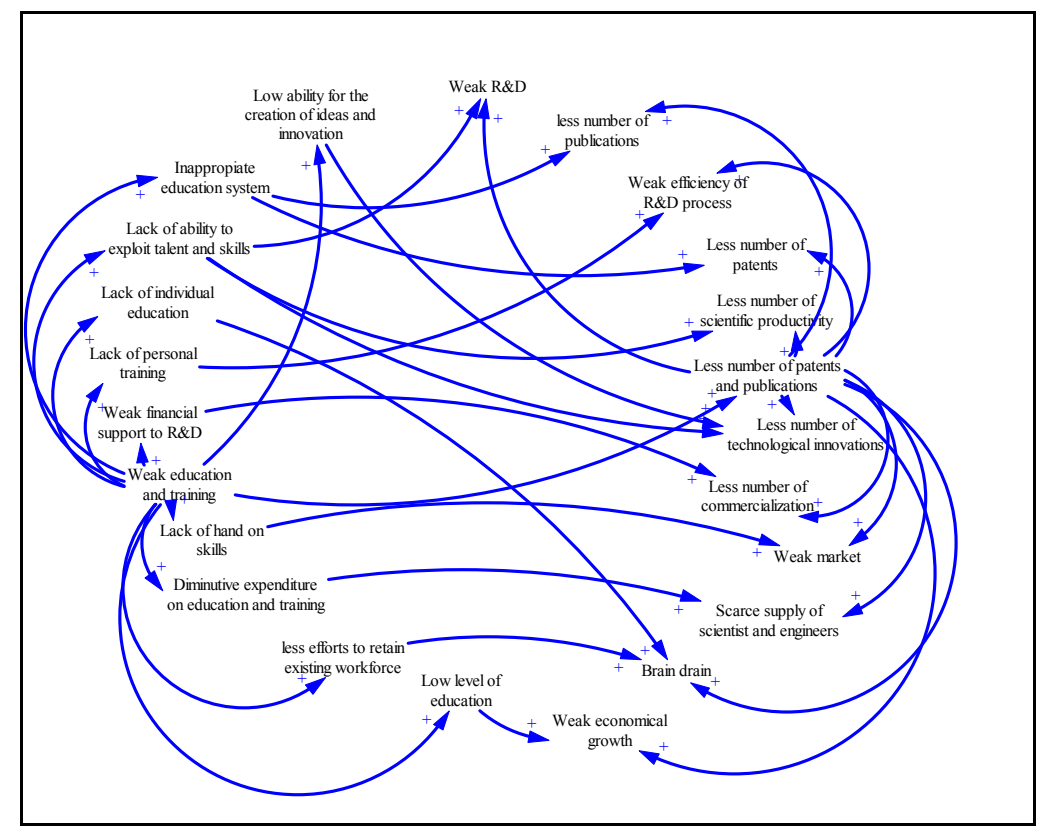

Figure 6. Education and training and patents and publications influence diagram

\section{d) Time constraints and lack of technological competency between UIRC, low absorptive capacity and number of patents and less commercialization.}

Commercialization is considered a prime example for generating heavy income for industries because it constitutes immediate, measureable market acceptance (Markman et al., 2008). Industries provide huge funding to universities to approach their innovation and convert in to commercialized product as they much aware about the process of commercialization. Unfortunately, industry and university do research on markedly different time frame. Industry is driven by economic and product cycle, while academic research project duration depends largely on time required for a graduate degree program (a year and a half to two years for master's degree, three to four years for doctorate). The longer time frame in universities cannot provide immediate research results to industry. In case of university's late response and due to lack of technological competency and absorptive capacity, industry cannot produce their product on time. On the contrary side, due to lack of knowledge and awareness of commercialization and due to time constraints, universities just filed their research in patent filing 
that increase the number of patents but not valuable for commercialization. Figure 7 shows the negative effect of lack of time constraints on patents and commercialization. While figure 8 shows the negative effect of lack of technological competency on absorptive capacity.

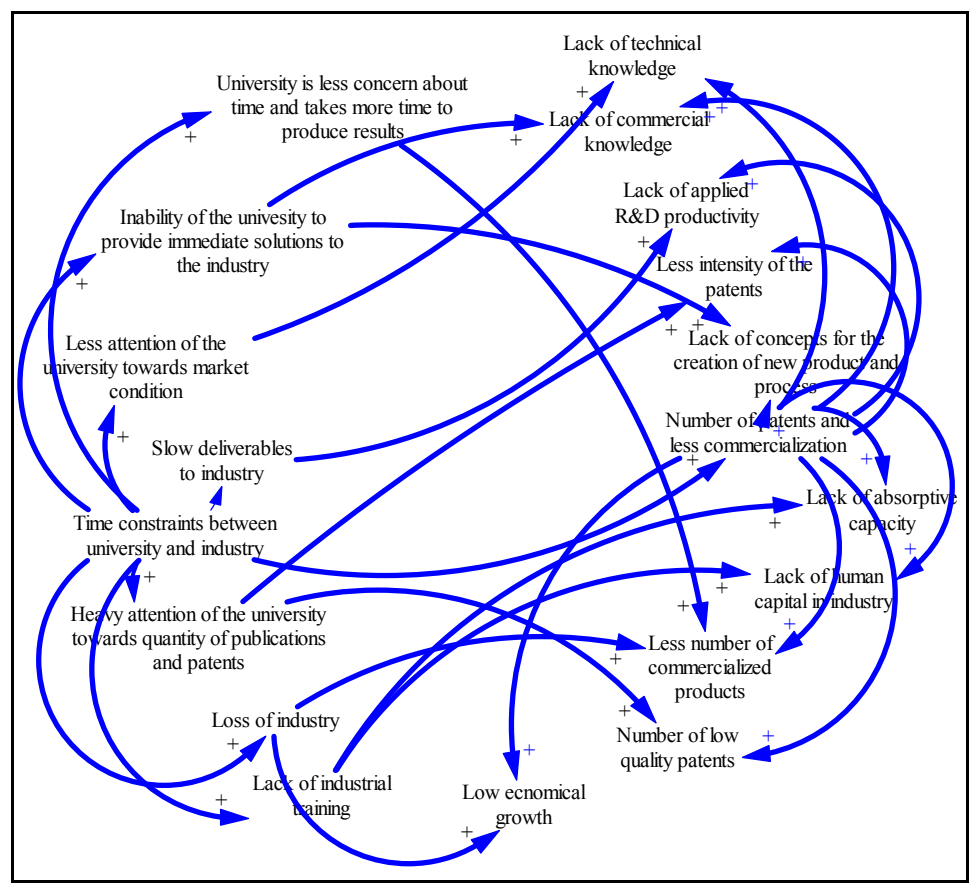

Figure 7. Time constraints on patents and commercialization influence diagram

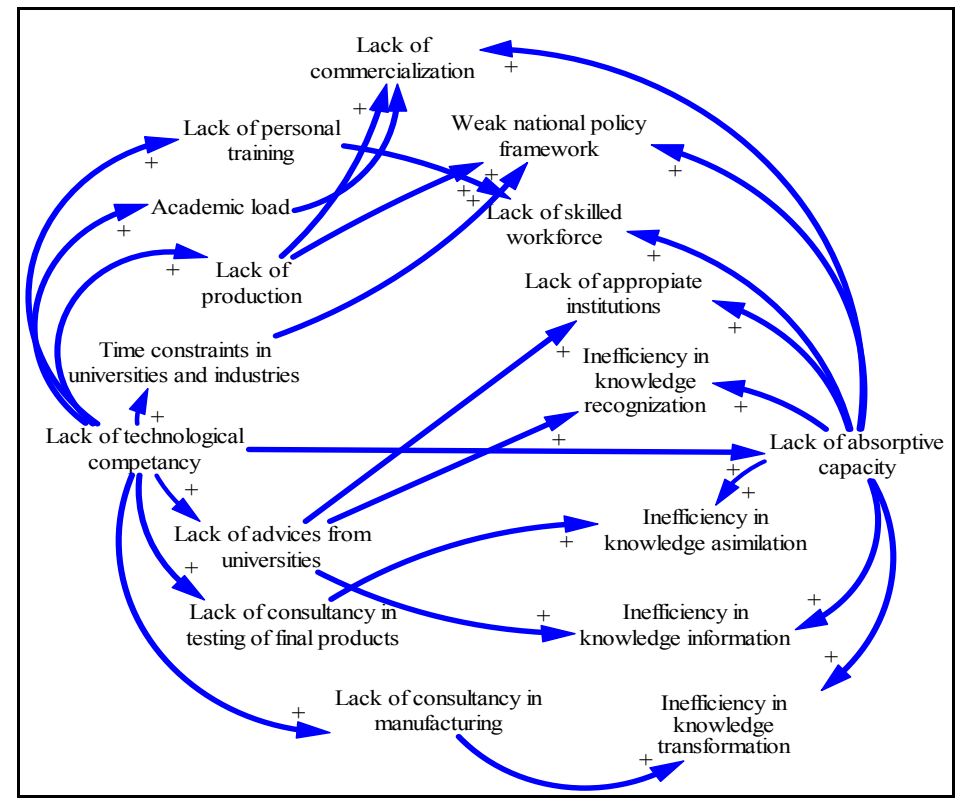

Figure 8 . Technological competency and absorptive capacity influence diagram

\section{e) Conflict of intellectual property right between UIRC and weak national IPR system.}

Patents and scientific publication activities remain a central part of a nation's innovation system, forming an extremely important aspect that signals the health of the innovation process. One of the clearest indicators of innovation performance is the rate of take-up of patents issued by the U.S. Patent and Trademarks Office (USPTO). Intellectual property rights are widely recognized as providing a reliable and unbiased indicator of the effort being expended on innovation by a country (Griliches, 1990; Trajtenberg, 1990). However, a more recent 
"anti-commons" perspective argues that the expansion of IPR (in the form of patents and/or copyrights) is "privatizing" the scientific commons and limiting scientific progress (Krimsky, 2003). Specifically, the anti-commons hypothesis states that IPR may inhibit the free flow and diffusion of scientific knowledge and the ability of researchers to build cumulatively on each other's discoveries (Krimsky, 2003). Dodgons et al. (2008), explain in his research that it is very common in developing countries that any research outcomes generated by the public institutions are required firstly to be diffused or licensed to local companies rather than taking global market demand. Dodgons further explain that lack of knowledge about IPR between public and private sector lessen the innovation capability thereby hinder the creation of innovation, resulting in a scarce of patents and commercialization. Figure 9 shows the negative effect of conflict of IPR between UIRC on national IPR system.

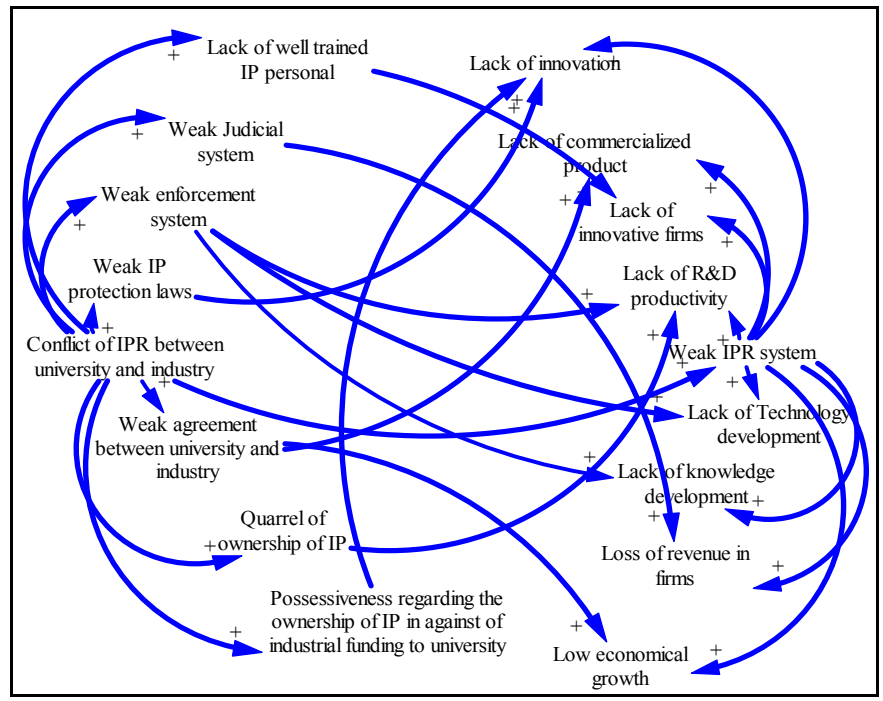

Figure 9. Conflict of IPR and national IPR system influence diagram

f) Lack of consultancy between UIRC and number of patents and less commercialization.

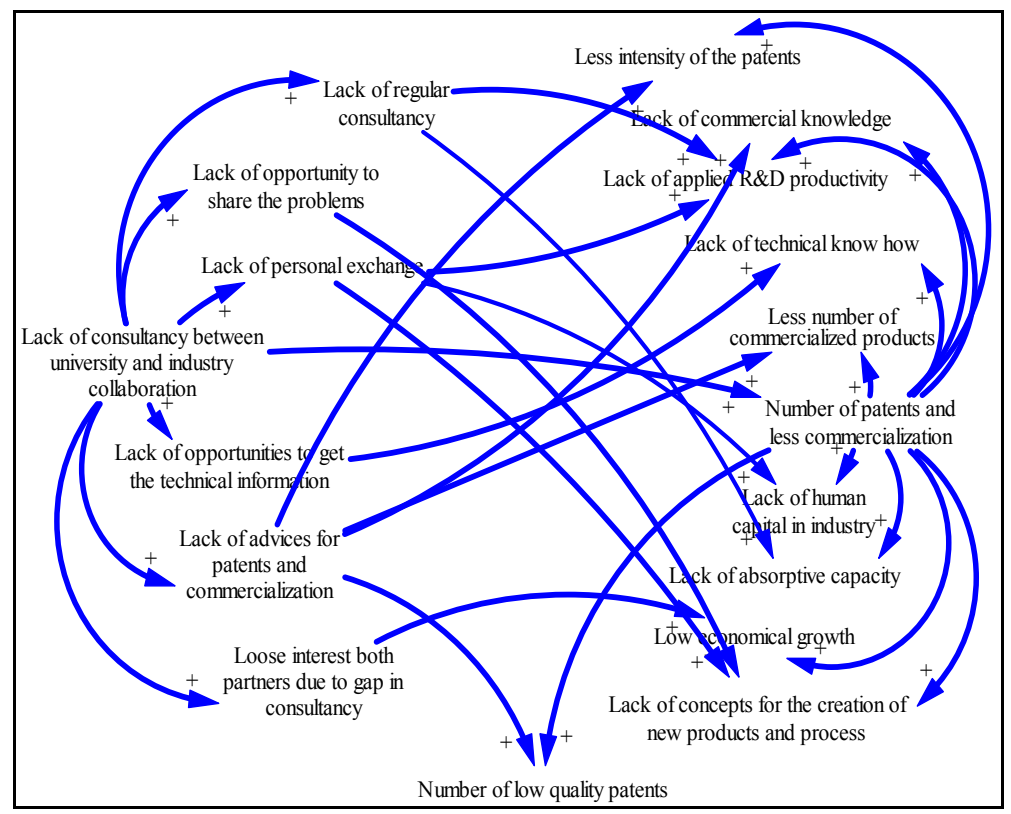

Figure 10. Consultancy on patents and commercialization influence diagram

University-industry relationships is increasingly recognized, attention has shifted to forms of interaction that involve direct collaboration between academics and industry (Cohen et al., 2002; Perkmann \& Walsh, 2007). Such collaboration encompasses licensing with inventor collaboration (Agrawal, 2002), university-industry 
research centres (Adams et al., 2001) and collaborative research (Behrens \& Gray, 2001). Among these collaborative forms of interaction, commercialization driven-consultancy is widely practiced. Commercialization of university patent has become a major issue around the world, where many universities are moving into technological and research based universities. Even though the university possessed a number of patents still a big portion of them are yet to commercialized (Ismail, 2011). Academics are specialists in certain areas of expertise and firms therefore engage them to resolve specific problems to speed up the process of commercializing the latest discoveries (Gibbons \& Johnston, 1974; Agrawal \& Henderson, 2002). Many universities encourage staff to provide consulting by allowing them to spend usually $20 \%$ of their time on outside activities (Schmoch, 1999). In the UK, total university income from consulting translated into an average of GBP 2458 per academic staff member in 2006 (HEFCE, 2007). An average US full-time faculty member earned an additional annual income of approximately USD 2200 in 2003 . Observers estimate that more than half of engineering faculty at the top 20 US research universities spend $10-15 \%$ of their time on consulting (Abramson et al., 1997). On contrast, developing countries like Malaysia still lag to approach this opportunity. Universities in developing countries still focusing more on teaching and learning mission. Surveys also suggest that most of the academics hesitate to engage with industry, fearing that pedagogic mission might distract from industrial relevance (Howells et al., 1998; Lee, 1996). This perception limits the service of consultancy between university and industry. Due to lack of consultancy industries cannot solve the issues that emerge in the discoveries to convert into commercialized product. Thus, Figure 10 shows the negative effect of lack of consultancy between UIRC on patents and commercialization.

\section{g) Culture difference between UIRC and lack of private sector involvement in $R \& D$.}

The university system is rooted in Mertonian norms of science, such as communalism, universalism, disinterestedness and organized scepticism (Merton, 1973). The creation of reliable and public knowledge has been central to the growth of these organizations, (Geuna et al., 2003). The priority of establishing reputation through publication is critical to academic success and/or career sustainability. Academics often have to engage in 'status competitions' with their peers, based on publication records, institutional affiliations and prizes (Becher, 1989). Many of these competitions take the form of winner-takes-all, in which publishing first or winning the largest research grants precludes others from these same achievements or resources. Given this environment, much of the science system is driven by internal dynamics that are separate from market transactions (Dasgupta \& David, 1994; Stephan, 1996). In contrast to the relatively open nature of the science system, the process of knowledge creation in the private sector is dominated by attempts to appropriate the economic value of what firms know in order to gain competitive advantage (Teece, 1986). This 'private' knowledge is largely closed, remaining hidden within the firm or disclosed in a limited way through patents filed primarily for the purposes of obtaining temporary monopolies (Allen, 1984; Dasgupta \& David, 1994). Thus, figure 11 shows the negative effect of culture difference between UIRC on private sector involvement in R\&D.

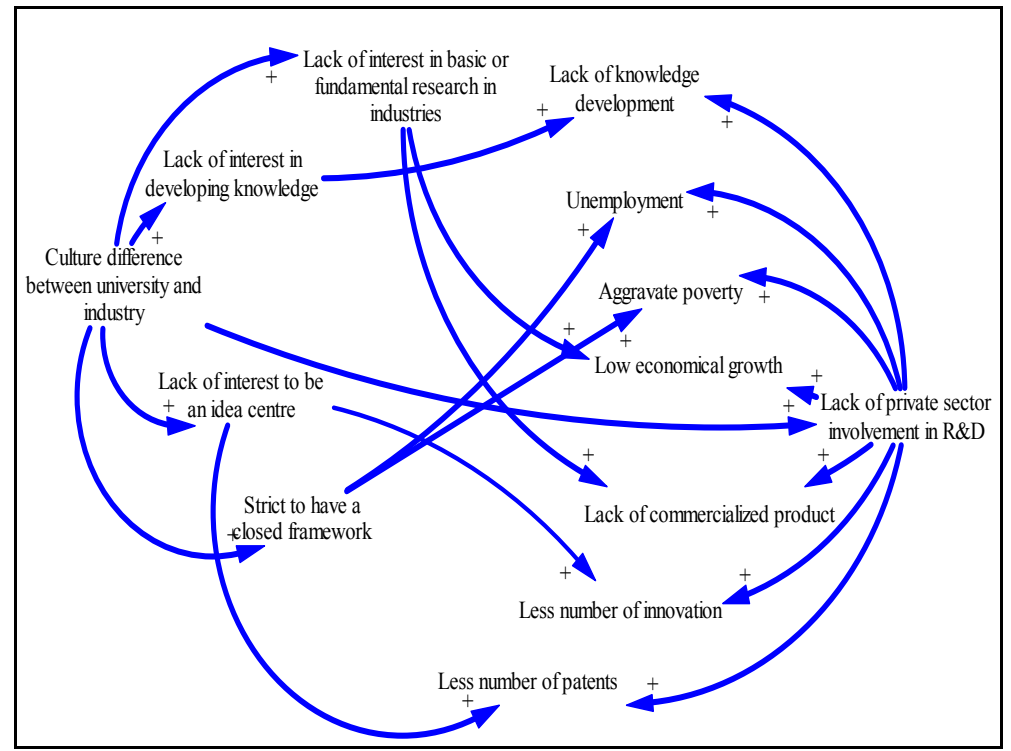

Figure 11. Culture difference and private sector involvement in R\&D influence diagram 


\section{h) Fund and financial matter between UIRC, low investment in $R \& D$ and high dependencies on FDI.}

Investment in $R \& D$ is an important factor in the development of innovation capabilities; innovation performance also depends critically on conditions that foster technology entrepreneurship, the availability of technical talent, and well-functioning product and capital markets (Freeman, 1987; Saeidi, 2015). Research and development is considered to be a primary resource for wealth creation and economic growth (Drucker, 1993; Nonaka \& Takeuchi, 1995). The role of the university as an economic and social institution has become increasingly important (Florida \& Cohen, 1999). Universities have long been involved in so-called 'third-stream' activities (Geuna \& Muscio, 2009), and there is evidence that they have significantly contributed to economic development and firm competitiveness. However, a deeper connection between university and industry is being seen as essential, and this requires a structural change in the role of universities within the national innovation system as well as a modernization of their managerial and organizational skills (European Commission, 2009). The expectation is that universities not only produce new knowledge, but that this knowledge be related to established social and economic targets (Laredo, 2007). In this view, universities should (a) intensify their involvement in the economic and social development; (b) increase the commercialization of research results, patenting and licensing activities; (c) institutionalize spin off activities; (d) introduce managerial and attitudinal changes among academics with respect to collaborative projects with industry (Van Looy et al., 2004).

With all these services it was plausible for universities to imagine that funding from the government would rise, but opposite happened, since 1970s government reduced funding to universities (Kok et al., 2010). This changed behavior forces the universities to collaborate with industries. Industries provide funding to university for the development of new research but expect a commensurate return on the bases of their investment (Matheis \& slaughter, 2013). Such as IP rights, on time outputs and the authorization of publications, commercialization, patenting and licensing. In these cases university loss their freedom and autonomy and cannot proceed the collaboration for long time (Van Dierdonck et al., 1990). These all phenomena increase the country's dependencies on FDI that directly and indirectly affect the human capital and absorptive capacity of the nation (Ahmed, 2012). Figure 12 and 13 shows the negative effect of fund and financial matter between UIRC on investment in R\&D and FDI.

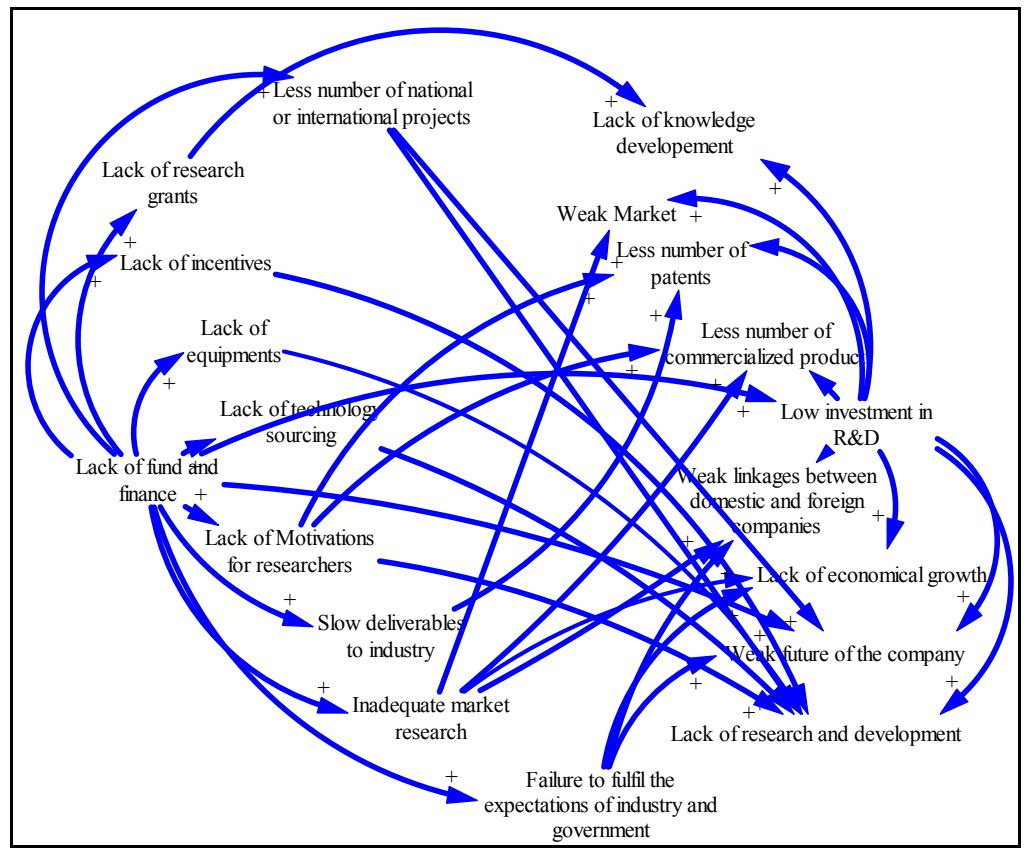

Figure 12. Fund and financial matter and investment in R\&D influence diagram 


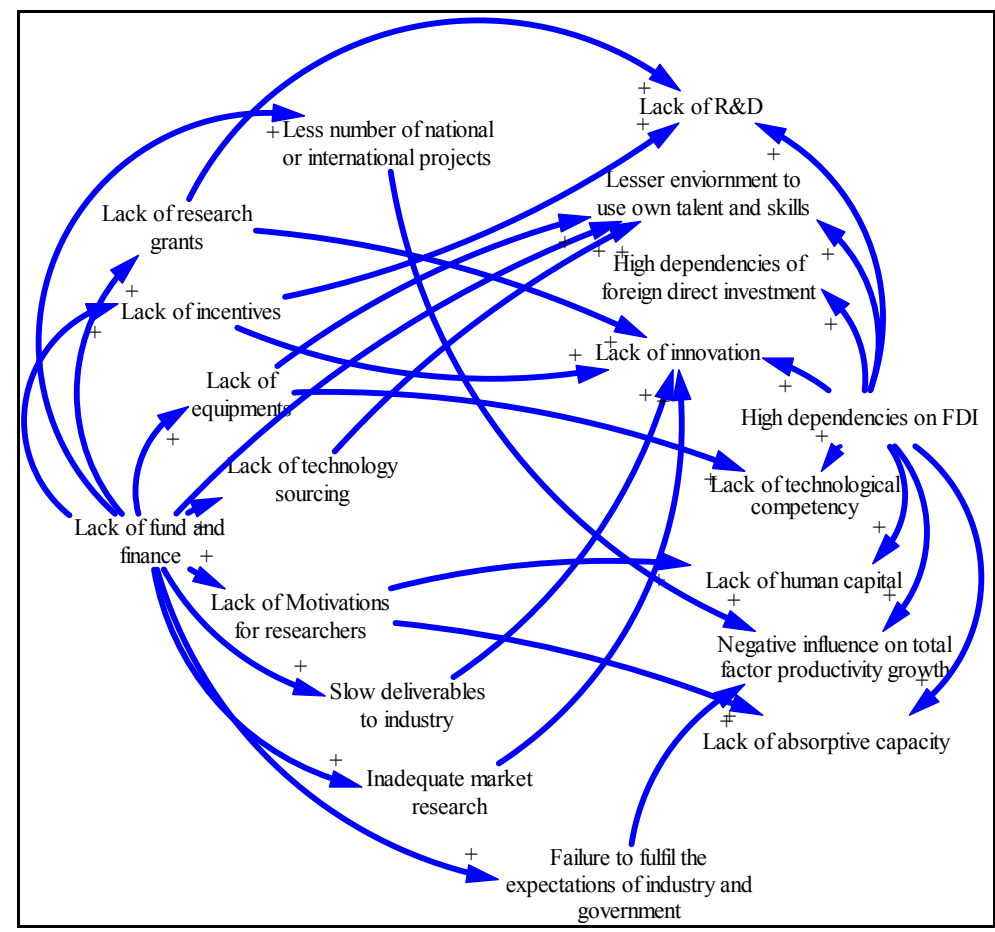

Figure 13. Fund and financial matter and FDI influence diagram

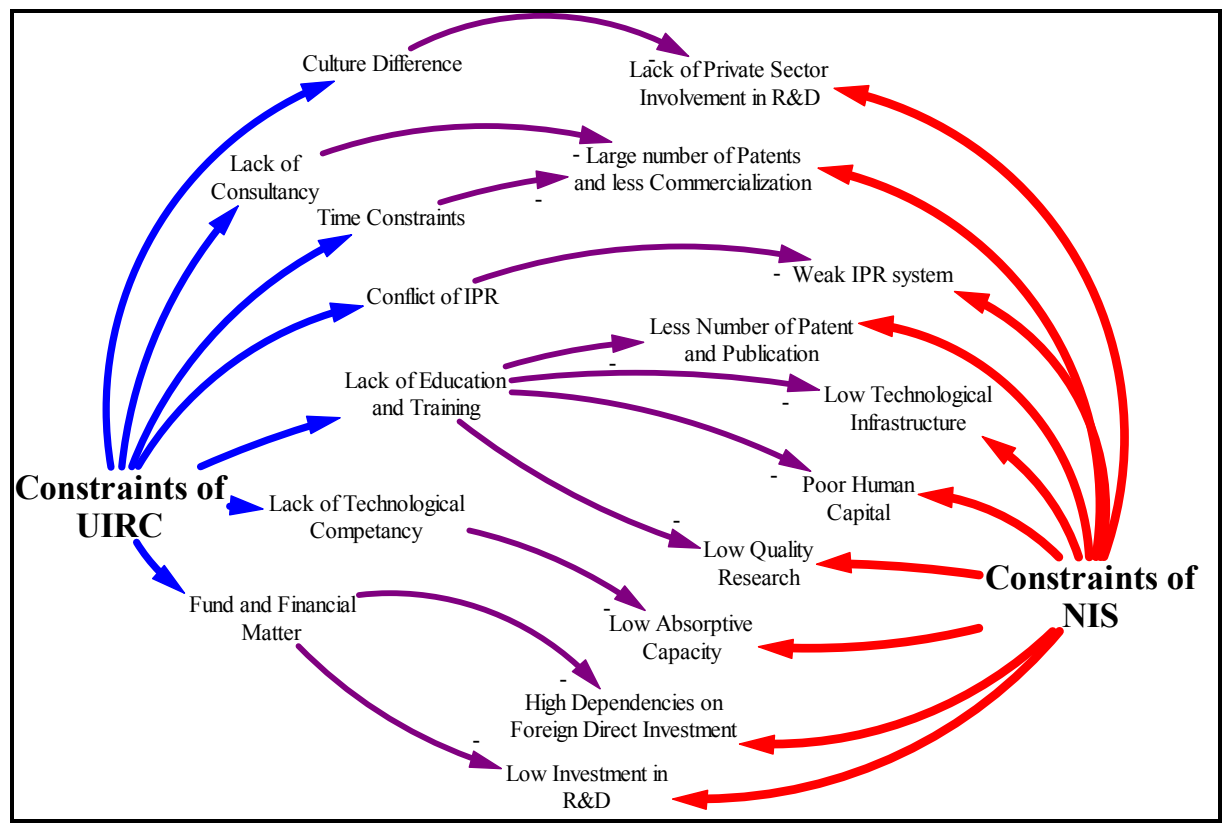

Figure 14. Evaluation model of NIS based on UIRC influence diagram

\section{Discussion and Conclusion}

Evaluation model Figure 14 provides a general understanding of the relations between different factors that form an innovation system. Transforming this model, System Dynamics Software Package has been used. This dynamic model shows the overall effect of constraints of UIRC on NIS. The detail of each factor however, gives us the ability to study all the elements that are involved in an innovation system and to analyze the influences.

Several theories and models about evaluation of NIS offer a framework under which the strength of innovation system can assess according to their best practices (see for example, Fritsch, 2006; Kravtsova \& Radosovic, 2012). These evaluation models provide linear perspective of the innovation system. These tools however, 
because they do not illustrate the fundamental cause of the weak innovation system, make it difficult for analysts and policy makers to understand the long-term influence of their decisions. Additionally, policy makers seek decisions that bring short-term results because these are directly visible to them. Solutions with short-term results however may reduce innovation activity in the longer-term and increase the problems that originally they were trying to solve (Galanakis, 2006). For example, it is often observed that government decide to cut research costs and research spending, in order to improve short-term financial results. This decision however may result in long-term losses of creative and innovative ideas and the inability to react to technological progress, which will effectively worsen the financial results of the country (Hamel \& Prahalad, 1994). The overall influence diagrams illustrate this consideration and the complete loop of the effects of different elements of the system will help the policy makers to realize the consequences of their decisions.

Concluding, this paper proposes a new innovation systems description using a systems thinking approach. The study aimed to evaluate the national innovation system of Malaysia based on university-industry research collaboration. For this purpose system dynamics were utilized to conceptualize the influence diagram that is possible only with the system thinking approach. Initially the research explored all the current constraints of NIS and UIRC of Malaysia and then illustrated the effect of UIRC on NIS by showing Influence (Loop) diagram explicitly. These diagrams represent the forces that occur in a system and between its parts. The essential idea behind the influence diagrams is an information-action-consequences paradigm. In this paradigm the consequences are always physical in the sense that something flows in the system. The recognition of what flows in the system is the key element to a good model (Coyle, 1996). Thus, by analyzing each diagram of this research, it has been concluded that university-industry research collaboration negatively influence on the success of NIS.

\section{Acknowledgements}

Author would like to thank Faculty of Management and Research Management Center of Universiti Teknologi Malaysia for their partial funding and contribution.

\section{References}

Abramson et al. (1997). Technologies transfer-System in den USA und Deutschland. Karlsruhe/Washington D.C.: Fraunhofer IRB Verlag.

Adams, J. D., Chiang, E. P., \& Starkey, K. (2001). Industry-University Cooperative Research Centers. Journal of Technology Transfer, 26(1/2), 73-86. http://dx.doi.org/10.1023/A:1007836328722

Agrawal, A., \& Henderson, R. M. (2002). Putting patents in context: Exploring knowledge transfer from MIT. Management Science, 48(1), 44-60. http://dx.doi.org/10.1287/mnsc.48.1.44.14279

Ahmed, E. M. (2012). Are the FDI inflow spillover effects on Malaysia's economic growth input driven? Economic Modeling, 29(4), 1498-1504. http://dx.doi.org/10.1016/j.econmod.2012.04.010

Asgari, B. (2007). Depicting the technology and economic development of Modern Malaysis. Asian Journal of Technology Innovation, 15(1), 167-193. http://dx.doi.org/10.1080/19761597.2007.9668634

Autant-Bernard, C., Fadairo, M., \& Massard, N. (2013). Knowledge diffusion and innovation policies within the European regions: Challenges based on recent empirical evidence. Research Policy, 42(1), 196-210. http://dx.doi.org/10.1016/j.respol.2012.07.009

Azizan, S. A. (2013). Strengthening Malaysia's Scientific and Technological Development through Human Capital Development. Procedia - Social and Behavioral Sciences, 91, 648-653. http://dx.doi.org/10. 1016/j.sbspro.2013.08.465

Bashir, F., Iqbal, A. M., Iqbal, S., Khan, A. S., \& Senin, A. A. (2013). The Critical Factors for the Successful Transformation of Technology from Developed to Developing Countries, 64(3), 105-108.

Beaudry, C., \& Allaoui, S. (2012). Impact of public and private research funding on scientific production: The case of nanotechnology. Research Policy, 41(9), 1589-1606. http://dx.doi.org/10.1016/j.respol.2012.03.022

Becher, T. (1989). Academic tribes and territories - intellectual enquiry and the cultures of disciplines. The Society for Research into Higher Education \& the Open University, Milton Keynes.

Becker, G. S. (1993). Human Capital: A Theoretical and Empirical Analysis with Special Reference to Education (3rd ed.). Chicago: University of Chicago Press. http://dx.doi.org/10.7208/chicago/9780226041223. 001.0001

Behrens, T. R., \& Gray, D. O. (2001). Unintended consequences of cooperative research: Impact of industry 
sponsorship on climate for academic freedom and other graduate student outcome. Research Policy, 30(2), 179-199. http://dx.doi.org/10.1016/S0048-7333(99)00112-2

Boardman, P. C. (2009). Government centrality to university-industry interactions: University research centers and the industry involvement of academic researchers. Research Policy, 38(10), 1505-1516. http://dx.doi.org/10.1016/j.respol.2009.09.008

Boons et al. (2013). Sustainable innovation, business models and economic performance: An overview. Journal of Cleaner Production, 45, 1-8. http://dx.doi.org/10.1016/j.jclepro.2012.08.013

Castellacci, F., \& Natera, J. M. (2013). The dynamics of national innovation systems: A panel cointegration analysis of the coevolution between innovative capability and absorptive capacity. Research Policy, 42(3), 579-594. http://dx.doi.org/10.1016/j.respol.2012.10.006

Chandran VGR, R. R., \& Wad, P. (2009). Malaysian manufacturing systems of innovation and internationalization of $R \& D$. Centre for business and development studies working paper series No. 11, Copenhagen, Denmark.

Checkland, P. B. (1999). System Thinking, System Practice. John Wiley and Sons, Chichester, England.

Chen, Z., \& Guan, J. (2010). The impact of small world on innovation: An empirical study of 16 countries. Journal of Informatics, 4(1), 97-106. http://dx.doi.org/10.1016/j.joi.2009.09.003

Coyle, R. G. (1996). System Dynamics Modeling. A Practical Approach. Chapman \& Hall, London. http://dx.doi.org/10.1007/978-1-4899-2935-8

Dasgupta, P., \& David, P. A. (1994). Toward a new economics of science. Research Policy, 23(4), 87-521.

Dodgson, M. D. G., \& Salter, A. (2008). The Management of Technological Innovation. Oxford: Oxford University Press.

Drucker, P. F. (1993). Post capitalist Society. New York: HarperCollins Publishers.

Eid, A. (2012). Higher education R\&D and productivity growth: An empirical study on high-income OECD countries. Education Economics, 20(1), 53-68. http://dx.doi.org/10.1080/09645291003726855

European Commission. (2009). The 2009 ageing report: Underlying assumptions and projection methodologies. European Economy, 7, 2009.

Fiaz, M. (2013). An empirical study of university-industry R\&amp; D collaboration in China: Implications for technology in society. Technology in Society, 35(3), 191-202. http://dx.doi.org/10.1016/j.techsoc. 2013.03.005

Fiedler, M., \& Welpe, I. M. (2010). Antecedents of cooperative commercialisation strategies of nanotechnology firms. Research Policy, 39(3), 400-410. http://dx.doi.org/10.1016/j.respol.2010.01.003

Flett, P. (2001). The role of Quality in the Management of Projects. Thesis.

Forrester, J. W. (1961). Industrial Dynamics. MIT Press, Cambridge, MA.

Fritsch, \& Slavtchev. (2007). What determines the efficiency of regional innovation systems. Jena Economic Research Papers. http://dx.doi.org/10.2139/ssrn.1018593

Galanakis. (2006). Innovation process. Make sense using systems thinking. Technovation, (26), 1222-1232.

Geuna, A., \& Muscio, A. (2009). The governance of university knowledge transfers Minerva, 47(1), 93-114. http://dx.doi.org/10.1007/s11024-009-9118-2

Govindaraju, V. G. R., \& Wong, C. Y. (2011). Patenting activities by developing countries: The case of Malaysia. World Patent Information, 33(1), 51-57. http://dx.doi.org/10.1016/j.wpi.2010.01.001

Griliches. (1992). The search for R\&dD spillovers. Scandinavian. Journal of Economic Behavior \& Organization, 29-47.

Heng, L. H., Rasli, A. M., \& Senin, A. A. (2012). Knowledge Determinant in University Commercialization: A Case Study of Malaysia Public University. Procedia - Social and Behavioral Sciences, 40, 251-257. http://dx.doi.org/10.1016/j.sbspro.2012.03.187

Hu, M. C., \& Tseng, C. Y. (2007). Technological Interdependence and Knowledge Diffusion in the Building of National Innovative Capacity: The Role of Taiwan's Chemical Industry. Technological Forecasting and Social Change, 74(3), 298-312. http://dx.doi.org/10.1016/j.techfore.2006.04.001

Iqbal, A. M., Khan, A. S., \& Senin, A. A. (2015a). An Efficient Evaluation Model for the Assessment of 
University-industry Research Collaboration in Malaysia. Research Journal of Applied Sciences, Engineering and Technology, 10(3), 2015.

Iqbal, A. M., Khan, A. S., \& Senin, A. A. (2015b). Reinforcing the National Innovation System of Malaysia based on University-industry Research Collaboration: A System Thinking Approach. International Journal of Management Sciences and Business Research, 4(1), 6-15.

Iqbal, A. M., Khan, A. S., Iqbal, S., \& Senin, A. A. (2011). Designing of Success Criteria-based Evaluation Model for Assessing the Research Collaboration between University and Industry. International Journal of Business Research and Management, 2(2), 59-73.

Iqbal, A. M., Khan, A. S., Iqbal, S., \& Senin, A. A. (2013). A Novel Cost Efficient Evaluation Model for Assessing Research-Based Technology Transfer between University and Industry. Jurnal Teknologi, 64(2), 87-91. http://dx.doi.org/10.11113/jt.v64.2242

Iqbal, S., Iqbal, A. M., Khan, A. S., \& Senin, A. A. (2013). A Modern Strategy for the Development of Academic Staff Based on University-industry Knowledge Transfer Effectiveness \& Collaborative Research. Jurnal Teknologi, 64(3), 35-38. http://dx.doi.org/10.11113/jt.v64.2262

Ismail, K. (2011). Commercialization of University Patents: A Case Study. Journal of Marketing Development and Competitiveness, 5(5), 80-91.

Jin et al. (2011). Progress in the production and application of n-butanol as a biofuel. Renewable and Sustainable Energy Reviews, 15(8), 4080-4106. http://dx.doi.org/10.1016/j.rser.2011.06.001

Kok, S. K., Douglas, A., \& McClelland, B. D. (2010). The Move Towards Managerialism: Perceptions of staff in "traditional" and "new" UK universities. Tertiary Education and Management, 16(2), 99-113. http://dx.doi. org/10.1080/13583881003756740

Kravtsova, V., \& Radosevic, S. (2012). Are systems of innovation in Eastern Europe efficient? Economic Systems, 36(1), 109-126. http://dx.doi.org/10.1016/j.ecosys.2011.04.005

Krimsky, S. (2003, August). Science and the Private Interest. Rowman-Littlefield Publishing Co., Lanham.

Lanciano, M. C., \& Nohara, H. (2002). The scientific labor market in international perspective: A 'bridging institution' between academia and industry for the co-operation and transfer of knowledge and competences' SASE 2002Conference Work and Labor in the Global Economy, University of Minnesota, Minneapolism Minnesota June 27-June 30, 2002.

Laredo, P. (2007). Revisiting the Third Mission of Universities: Toward a Renewed Categorization of University Activities? Higher Education Policy, 20, 441-456. http://dx.doi.org/10.1057/palgrave.hep.8300169

Lee, Y. S. (1996). 'Technology transfer' and the research university: A search for the boundaries of university-industry collaboration. Research Policy, 5(6), 843-863. http://dx.doi.org/10.1016/0048-7333 (95)00857-8

Markman, G. D., Gianiodis, P. T., \& Phan, P. H. (2008). Full-time Faculty or Part-time Entrepreneurs. IEEE Transactions on Engineering Management, 55(1), 29-38. http://dx.doi.org/10.1109/TEM.2007.912813

Maruyama, M. (1963). The second cybernetics: Deviation amplifying mutual causal processes. American Scientist, 51(2), 164-179.

Marxt, C., \& Brunner, C. (2012). Analyzing and improving the national innovation system of highly developed countries - The case of Switzerland. Technological Forecasting and Social Change, 80(6).

Merton, R. K. (1973). The sociology of science: Theoretical and empirical investigations. University of Chicago Press, Chicago.

Metcalfe, S., \& Ramlogan, R. (2008). Innovation systems and the competitive process in developing economies. The Quarterly Review of Economics and Finance, 48(2), 433-446. http://dx.doi.org/10.1016/j.qref.2006. 12.021

Nonaka, I., \& Takeuchi, H. (1995). The Knowledge-Creating Company. New York: Oxford University Press.

Park, H. C., Hong, H. D., \& Leydesdorff, L. (2005). A Comparison of the Knowledge-based Innovation Systems in the Economies of South Korea and the Netherlands using Triple Helix Indicators, Scientometric, 65(1), 3-27. http://dx.doi.org/10.1007/s11192-005-0257-4

Perkmann, M., \& Walsh, K. (2008). Engaging the scholar: Three forms of academic consulting and their impact on universities and industry. Research Policy, 37(10), 1884-1891. http://dx.doi.org/10.1016/j.respol. 2008.07.009 
Pidd, M. (1998). Computer Simulation in Management Science (4th ed.). Wiley, New York.

Popescu, M., \& Crenicean, L. C. (2012). Innovation and Change in Education-Economic Growth Goal in Romania in the Context of Knowledge-Based Economy. Procedia-Social and Behavioral Sciences, 46, 3982-3988. http://dx.doi.org/10.1016/j.sbspro.2012.06.183

Ramli, N. (2013). The Concept of Research University: The Implementation in the Context of Malaysian University System. Asian Social Science, 9(5), 307-317. http://dx.doi.org/10.5539/ass.v9n5p307

Roberts, N., David, F. A., Deal, R. M., \& Michael, S. G. (1983). Introduction to Computer Simulation: The System Dynamics Approach. Addison-Wesley Publication Company, Reading, MA.

Robin, S., \& Schubert, T. (2013). Cooperation with public research institutions and success in innovation: Evidence from France and Germany. Research Policy, 42(1), 149-166. http://dx.doi.org/10.1016/j.respol. 2012.06.002

Saeidi, S. P., Sofian, S., Saeidi, P., Saeidi, S. P., \& Saaeidi, S. A. (2013). Moderating Effect of Environmental Management Accounting on Innovation and Firm Performance: Review of Contemporary Literature. $J$. Basic. Appl. Sci. Res., 3(11), 332-338.

Saeidi, S. P., Sofian, S., Saeidi, P., Saeidi, S. P., \& Saaeidi, S. A. (2015). How does corporate social responsibility contribute to firm financial performance? The mediating role of competitive advantage, reputation, and customer satisfaction. Journal of Business Research, 68, 341-350. http://dx.doi.org/10.1016/j.jbusres. 2014.06.024

Schmoch, U. (2007). Patentanmeldungen aus deutschen Hochschulen. Studien zum deutschen Innovations system, 10 .

Schultz, T. W. (1993). The economic importance of human capital in modernization. Education Economics, 1(1), 13-19. http://dx.doi.org/10.1080/09645299300000003

Senge, P. M. (1990). The Fifth Discipline, The art and practice of the learning organization (1st ed.). Doubleday, USA.

Smith, D. (2010).The Role of Entrepreneurship in Economic Growth. Undergraduate Economic Review, 6.

Teirlinck, P., \& Spithoven, A. (2013). Research collaboration and R\&amp; D outsourcing: Different R\&amp;D personnel requirements in SMEs. Technovation, 33(4-5), 142-153. http://dx.doi.org/10.1016/j.technovation. 2012.11.005

Tustin, A. (1953). The Mechanism of Economic Systems. Harvard University Press, Cambridge, MA.

Van Dierdonck, R., Debackere, K., \& Engelen, B. (1990). University-industry relationships: How does the Belgian academic community feel about it? Research Policy, 19, 551-566. http://dx.doi.org/10.1016/00487333(90)90012-U

Vu, T. A. (2012). An insight into the patent systems of fast developing ASEAN countries. World Patent Information, 34(2), 134-142. http://dx.doi.org/10.1016/j.wpi.2011.12.007

Wong, C. Y., \& Goh, K. L. (2012). The sustainability of functionality development of science and technology: Papers and patents of emerging economies. Journal of Informatics, 6(1), 55-65. http://dx.doi.org/10.1016/ j.joi.2011.07.001

Wong, C. Y., Thirucelvam, K., \& Ratnavelu, K. (2010). Diffusion trajectories of emerging sciences in Malaysian R\&amp;D system. Technological Forecasting and Social Change, 77(7), 1109-1125. http://dx.doi.org/10.10 16/j.techfore.2010.02.008

Wonglimpiyarat, J. (2011). Government programmes in financing innovations: Comparative innovation system cases of Malaysia and Thailand. Technology in Society, 33(1-2), 156-164. http://dx.doi.org/10.1016/j. techsoc.2011.03.009

\section{Copyrights}

Copyright for this article is retained by the author(s), with first publication rights granted to the journal.

This is an open-access article distributed under the terms and conditions of the Creative Commons Attribution license (http://creativecommons.org/licenses/by/3.0/). 